\title{
PLANO NACIONAL DE EDUCAÇÃO E SEUS DESDOBRAMENTOS SOBRE AS NOVAS DIRETRIZES PARA A FORMAÇÃO DE PROFESSORES DA EDUCAÇÃO PROFISSIONAL: IDENTIDADES PROFISSIONAIS EM CONSTRUÇÃO ${ }^{1}$
}

\author{
F. L. G. R. SILVA \\ Instituto Federal de Educação, Ciência e Tecnologia Catarinense/Campus Camboriú. Florianópolis/SC-Brasil \\ filomena@ifc-camboriu.edu.br
}

Artigo submetido em agosto/2016 e aceito em setembro/2016

DOI: $10.15628 /$ holos.2016.4986

\section{RESUMO}

O texto, baseado em análise documental e revisão bibliográfica, discute as relações entre o Plano Nacional de Educação (PNE) aprovado pela Lei no 13.005, de 2014, e as novas Diretrizes para a formação inicial e continuada de professores da Educação Básica, Resolução 02, de 2015. Além disso, discute os impactos das políticas educacionais sobre a construção/fabricação da identidade profissional dos professores da Educação Profissional e Tecnológica (EPT). As reflexões realizadas permitem-nos concluir que a aprovação de tais diretrizes contribui para o alcance da Meta 15 do PNE (que trata da implantação de uma Política Nacional de Formação de Professores) e da sua estratégia 15.9 (que versa sobre a implantação de cursos e programas especiais de formação para os professores não licenciados e em efetivo exercício na docência). Entretanto, não ultrapassam a perspectiva histórica de políticas provisórias e emergenciais para a formação de professores da EPT, apesar de avançarem em relação a carga horária e a concepção que a orienta. Os dados analisados nos possibilitam verificar ainda que a ausência de políticas contínuas de formação de professores para a EPT produziram um índice de $63,25 \%$ dos professores da Educação Profissional Técnica De Nível Médio (dados do Censo Escolar de 2012) sem a formação legalmente estabelecida para a docência, produzindo impactos sobre a construção/fabricação da sua identidade profissional que, no atual contexto, alinha-se ao projeto nacional em desenvolvimento, comprometido com os interesses do sistema produtivo capitalista.

PALAVRAS-CHAVE: Plano Nacional de Educação (2014-2024), Formação de Professores, Educação Profissional.

\section{NATIONAL PLAN OF EDUCATION AND THE OUTCOME ABOUT THE NEW DIRECTIVES FOR THE PROFESSIONAL EDUCATION TEACHERS' FORMATION: PROFESSIONAL IDENTITES IN DEVELOPMENT}

\begin{abstract}
This text, based on documental analysis and bibliographical research, discusses the relations between the National Plan of Education (PNE) approved by the law 13.005, in 2014, and the new Directives for initial and continuous formation of Basic Education Teachers, Resolution 02, in 2015. Also, it discusses on impacts of the educational policies about the construction/fabrication of the professional identity of Vocational and Technological Education Teachers (EPT). The discussions allow us to conclude that the approval of such directives contribute on the achievement of PNE Aim 15 (Meta 15 do PNE). It deals with the implementation of a Teachers' Formation National Policy and the Strategy 15.9 deals about the implementaiton of special courses and programmes for the teachers' formation - teachers that do
\end{abstract}

not possess a specific graduation for teaching. However, these changes do not surpass the historical perspective of temporary and urgent policies for Professional Education Teachers' Formation, but they show some advances about academic working hours and the conceptions supporting them. The analysis of the data verified that there is no permanent or continuous policies for teachers in Professional Education. This lack of policies originated $63,25 \%$ of Vocational Integrated Professional Education Teachers without a legal formation for teaching. It caused impacts on the development of the construction/fabrication of a professional identity that, within the context, matches the national project for development committed with the interests of the productive capitalist system.

KEYWORDS: National Plan of Education (2014-2024), Teachers' Formation, Professional Education.

\footnotetext{
${ }^{1}$ Texto elaborado a partir da tese de doutorado da autora "Identidade profissional dos professores da Educação Profissional Técnica de Nível Médio no Brasil e em Santa Catarina: desafios para a sua formação", orientada pela Profa Dra Leda Scheibe/Programa de Pós-Graduação em Educação da Universidade Federal de Santa Catarina - PPGE/UFSC.
} 


\section{INTRODUÇÃO}

A defesa acerca da urgência de uma política orgânica de formação de professores para a Educação Básica de maneira geral e particularmente da Educação Profissional e Tecnológica (EPT) tem sido recorrente nas últimas décadas. A constatação, e por que não dizer denúncia, de que a formação de professores para a EPT tem sido alvo de medidas paliativas, aligeiradas e emergenciais estão presentes nas produções teóricas referentes a formação de professores e das políticas de Educação Profissional tanto de pesquisadores/intelectuais da área (Lucília Machado, Dante Moura, Acácia Kuenzer, Maria Ciavatta, Marise Ramos, Gaudêncio Frigotto, Leda Scheibe, Gabriel Grabowski, entre outros) quanto em estudos/pesquisas em nível de mestrado e doutorado país afora.

A análise de tais produções teóricas e estudos permitem-nos afirmar que as políticas de formação de professores vinculam-se e se comprometem com diferentes manifestações da política social e, como tal, configuram-se em um movimento contraditório entre as forças sociais em disputa no país. Compreender essa relação significa entender as políticas de formação de professores como "estratégica para a construção do projeto nacional em desenvolvimento" (SCHEIBE, 2008a, p 42).

Além disso, a análise e reflexão a respeito das políticas de formação de professores para a Educação Profissional e Tecnológica possibilitam a percepção da existência de uma forte relação entre a configuração das políticas com o projeto societário em construção em cada momento histórico e que estas influenciam tanto a fabricação das identidades profissionais desses professores quanto dos profissionais que estes 'formam'.

A esse respeito, cabe registrar também que, como as demais políticas sociais, as políticas educacionais abrangem um amplo conjunto de atores, embora sua expressão maior se dê por meio de iniciativas direta ou indiretamente promovidas pelo poder público. Mais do que como um produto, no entanto, é preciso captá-la como um processo que implica negociações, contestação e luta entre diferentes grupos que, de alguma forma, envolvem-se na sua discussão, mesmo que não se envolvam diretamente na elaboração oficial da legislação (VIEIRA, 2002).

É nesse contexto que compreendemos que tanto a trajetória das políticas de formação de professores no Brasil e as políticas de Educação Profissional e Tecnológica em geral, em seus diferentes níveis (qualificação profissional, formação de nível médio em suas distintas formas de articulação com a educação básica, ensino superior e pós-graduação) e modalidades, quanto o Novo Plano Nacional de Educação - 2014/2024 (Lei no 13.005/2014), estão fortemente influenciados pelas forças sociais em disputa no país e impactam na construção ou fabricação da identidade profissional dos professores da EPT.

Feita essa breve introdução acerca do significado e das representações de uma política de formação de professores para um projeto de nação, esclarecemos que o texto está constituído por quatro partes afora a introdução.

Inicialmente discute-se a questão da formação de professores para a EPT no Plano Nacional de Educação e seus desdobramentos nas novas Diretrizes para a Formação de Professores. Em seguida, como forma de ilustrar os desafios que se põem para a formação de professores para a EPT nos próximos anos, caracterizaremos os docentes atuantes na Educação Profissional Técnica de Nível Médio no Brasil. Num terceiro momento faremos uma reflexão a respeito dos impactos das 
políticas educacionais e da socialização/trabalho docente na construção/fabricação da identidade profissional do professor da EPT. Finalmente, nas considerações finais destacamos alguns aspectos que podem alimentar o debate acerca da relação existente entre as políticas da EPT e de formação dos seus professores com a construção/fabricação da identidade profissional dos professores da EPT alinhada ao projeto nacional em desenvolvimento.

\section{A FORMAÇÃO DE PROFESSORES PARA A EPT NO PLANO NACIONAL DE EDUCAÇÃO E SEUS DESDOBRAMENTOS NAS NOVAS DIRETRIZES PARA A FORMAÇÃO DE PROFESSORES}

A publicação da Lei 13.005/2014 que aprovou o Plano Nacional de Educação 2014-2024, resulta de um longo período de debates e disputas e estabelece 20 metas e 240 estratégias que, em tese, constituem-se no principal instrumento de orientação para a construção das políticas educacionais no Brasil até 2024.

Em que pese a formação de professores para a Educação Básica, o Plano Nacional de Educação, por meio das metas 15 e 16, estabelece, respectivamente, as estratégias que focalizarão a formação inicial dos profissionais da educação (que deverá acontecer em nível superior) e a formação continuada.

Quanto a formação inicial dos profissionais da educação temos:

Meta 15: Garantir, em regime de colaboração entre a União, os Estados, o Distrito Federal e os Municípios, no prazo de 1 (um) ano de vigência deste PNE, política nacional de formação dos profissionais da educação de que tratam os incisos I, II e III do caput do art. 61 da Lei no 9.394, de 20 de dezembro de 1996, assegurado que todos os professores e as professoras da educação básica possuam formação específica de nível superior, obtida em curso de licenciatura na área de conhecimento em que atuam. (BRASIL, 2014)

A importância da meta é inquestionável, uma vez que se compromete com o estabelecimento de uma política de formação dos profissionais da educação no prazo de um ano da vigência do plano. Entre suas estratégias, fundamentalmente no que tange a formação de professores para a Educação Profissional, em certa medida vemos reprisada a indicação da implementação de cursos e programas especiais de formação e a valorização da experiência prática e certificação didático pedagógica de profissionais experientes, conforme segue:

15.9) implementar cursos e programas especiais para assegurar formação específica na educação superior, nas respectivas áreas de atuação, aos docentes com formação de nível médio na modalidade normal, não licenciados ou licenciados em área diversa da de atuação docente, em efetivo exercício;

15.13) desenvolver modelos de formação docente para a educação profissional que valorizem a experiência prática, por meio da oferta, nas redes federal e estaduais de educação profissional, de cursos voltados à complementação e certificação didático-pedagógica de profissionais experientes.

Transcorrido exatamente um ano da aprovação do Plano Nacional de Educação 2014-2024 tivemos aprovado no dia 09 de junho de 2015 o Parecer CNE/CP 02/2015 e no dia 10 de julho de 
2015 a Resolução n. 2/2015 que 'Define as Diretrizes Curriculares Nacionais para a formação inicial em nível superior (cursos de licenciatura, cursos de formação pedagógica para graduados e cursos de segunda licenciatura) e para a formação continuada'. Este parecer e resolução normatizam o previsto na meta 15 e corroboram para direcionar as ações das instituições que serão responsáveis pela viabilização das estratégias 15.9 e 15.13, expostas acima.

Vale dizer incialmente que a Resolução 02/2015 ao regulamentar a formação de profissionais do magistério para a educação básica ${ }^{2}$ reconhece que a instituição de normas nacionais são indispensáveis para a construção de um projeto nacional da educação brasileira, e que para garantir este projeto é necessário não só superar a fragmentação das políticas públicas, mas também a desarticulação institucional por meio da instituição do Sistema Nacional de Educação e a realização de cooperações e colaborações entre entes federados e sistemas educacionais' (BRASIL, 2015).

Outro fator relevante a ser mencionado antes de adentrarmos para a análise acerca do proposto para a formação de professores que atuam na Educação Profissional e Tecnológica, é o fato de que a Resolução 02/2015 reconhece que as instituições de educação básica, os seus processos de organização e gestão e os projetos pedagógicos cumprem um papel estratégico na formação requerida nas diferentes etapas (educação infantil, ensino fundamental e ensino médio) e modalidades da educação básica. Daí a importância do envolvimento dos sujeitos do processo de ensino e aprendizagem na elaboração dos Planos de Desenvolvimento Institucional, dos Projetos Pedagógicos das instituições e dos Projetos de cursos de formação, como também dos órgãos colegiados de gestão.

Quanto a concepção de docência, a Resolução 02/2015 expressa que esta constitui-se em uma ação educativa e um processo pedagógico intencional e metódico que envolve:

[...]conhecimentos específicos, interdisciplinares e pedagógicos, conceitos, princípios e objetivos da formação que se desenvolvem entre conhecimentos científicos e culturais, nos valores éticos, políticos e estéticos inerentes ao ensinar e aprender, na socialização e construção de conhecimentos, no diálogo constante entre diferentes visões de mundo'. (BRASIL, 2015).

No que se refere a concepção de currículo, tem-se a compreensão de que este envolve não somente a 'construção da identidade sociocultural do educando, seus direitos e deveres do cidadão', como também sinaliza para a necessidade de considerar 'a realidade concreta dos sujeitos que dão vida ao currículo e às instituições de educação básica, sua organização e gestão, os projetos de formação'. (BRASIL, 2015).

A concepção de educação, por sua vez, é de que esta se constitui num direito fundamental em e para os direitos humanos e, portanto, uma necessidade estratégica na formação dos profissionais do magistério e na ação educativa. No art. 3ํ, § 1ํㅡ, há a menção de que por educação entendem-se:

\footnotetext{
${ }^{2} \S 4$ ㅇ Os profissionais do magistério da educação básica compreendem aqueles que exercem atividades de docência e demais atividades pedagógicas, incluindo a gestão educacional dos sistemas de ensino e das unidades escolares de educação básica, nas diversas etapas e modalidades de educação (educação infantil, ensino fundamental, ensino médio, educação de jovens e adultos, educação especial, educação profissional e técnica de nível médio, educação escolar indígena, educação do campo, educação escolar quilombola e educação a distância), e possuem a formação mínima exigida pela legislação federal das Diretrizes e Bases da Educação Nacional.
} 
[...]os processos formativos que se desenvolvem na vida familiar, na convivência humana, no trabalho, nas instituições de ensino, pesquisa e extensão, nos movimentos sociais e organizações da sociedade civil e nas relações criativas entre natureza e cultura'. (BRASIL, 2015).

Fundamentada nestas concepções (de docência, de currículo e de educação), a Resolução 02/2015, Art. 3ㅇ, § 5 estabelece os seguintes princípios da Formação de Profissionais do Magistério da Educação Básica (BRASIL, 2015):

I - a formação docente para todas as etapas e modalidades da educação básica como compromisso público de Estado, buscando assegurar o direito das crianças, jovens e adultos à educação de qualidade, construída em bases científicas e técnicas sólidas em consonância com as Diretrizes Curriculares Nacionais para a Educação Básica;

II - a formação dos profissionais do magistério (formadores e estudantes) como compromisso com projeto social, político e ético que contribua para a consolidação de uma nação soberana, democrática, justa, inclusiva e que promova a emancipação dos indivíduos e grupos sociais, atenta ao reconhecimento e à valorização da diversidade e, portanto, contrária a toda forma de discriminação;

III - a colaboração constante entre os entes federados na consecução dos objetivos da Política Nacional de Formação de Profissionais do Magistério da Educação Básica, articulada entre o Ministério da Educação (MEC), as instituições formadoras e os sistemas e redes de ensino e suas instituições;

IV - a garantia de padrão de qualidade dos cursos de formação de docentes ofertados pelas instituições formadoras;

V - a articulação entre a teoria e a prática no processo de formação docente, fundada no domínio dos conhecimentos científicos e didáticos, contemplando a indissociabilidade entre ensino, pesquisa e extensão;

VI - o reconhecimento das instituições de educação básica como espaços necessários à formação dos profissionais do magistério;

VII - um projeto formativo nas instituições de educação sob uma sólida base teórica e interdisciplinar que reflita a especificidade da formação docente, assegurando organicidade ao trabalho das diferentes unidades que concorrem para essa formação;

VIII - a equidade no acesso à formação inicial e continuada, contribuindo para a redução das desigualdades sociais, regionais e locais;

IX - a articulação entre formação inicial e formação continuada, bem como entre os diferentes níveis e modalidades de educação;

$X$ - a compreensão da formação continuada como componente essencial da profissionalização inspirado nos diferentes saberes e na experiência docente, integrando-a ao cotidiano da instituição educativa, bem como ao projeto pedagógico da instituição de educação básica;

$\mathrm{XI}$ - a compreensão dos profissionais do magistério como agentes formativos de cultura e da necessidade de seu acesso permanente às informações, vivência e atualização culturais. 
Destacamos que tais princípios revelam uma mudança do referencial para a formação de professores até então em vigor, que esteve ancorada na concepção de desenvolvimento de competências profissionais. Compreende-se, a partir de tais princípios que a nova legislação que passa a regulamentar a formação dos profissionais da educação, em tese, vincula-se com uma perspectiva crítica, comprometida com a educação de qualidade social e com a emancipação dos indivíduos/sujeitos e grupos sociais.

Além do destaque aos princípios que passam a orientar a elaboração dos projetos de criação de cursos de formação inicial e continuada dos profissionais da educação, enfatizamos que nos $\S 2$ 응 e § 3ㅇ do Art. 1 da Resolução 02/2015 há a indicação de que as instituições de ensino superior e os centros de formação de estados e municípios e as próprias instituições de educação básica precisarão conceber esta formação como expressão de uma política articulada à educação básica, cabendo-Ihes considerar não só as Diretrizes Curriculares Nacionais como também o padrão de qualidade e o Sistema Nacional de Avaliação da Educação Superior (Sinaes) de forma que a formação demonstre organicidade com as políticas educacionais e o Planos de Desenvolvimento Institucional (PDI), o Projeto Pedagógico Institucional (PPI) e o Projeto Pedagógico de Curso (PPC).

Tal orientação permite-nos inferir que há uma pretensão de se estabelecer um alinhamento entre as políticas em âmbito federal com as políticas desenvolvidas pelos estados e municípios e as ações das instituições de ensino e centros de formação. Na prática, contudo, há que se repensar as ações que possam dar conta de tal perspectiva de modo que abranjam tanto os cursos de formação em andamento e aquelas que estão sendo gestadas. Dizemos isto especialmente em relação a formação dos profissionais da Educação da Educação Profissional, fundamentalmente os seus professores.

A título de exemplificação, chamamos a atenção para a adesão dos Institutos Federais a Chamada Pública UAB no 01/2013, de 14 de fevereiro de 2013, do Ministério da Educação/Coordenação de Aperfeiçoamento de Pessoal em Nível Superior (MEC/CAPES), para a oferta de cursos de especialização em Educação Profissional por meio da Educação à Distância, cuja estrutura da proposta contempla a indicação de habilidades e competências a serem desenvolvidas pelos egressos dos cursos.

Tal perspectiva para a formação, não condiz como o exposto no texto das novas Diretrizes que indicam que:

Art. 70 $O(A)$ egresso(a) da formação inicial e continuada deverá possuir um repertório de informações e habilidades composto pela pluralidade de conhecimentos teóricos e práticos, resultado do projeto pedagógico e do percurso formativo vivenciado cuja consolidação virá do seu exercício profissional, fundamentado em princípios de interdisciplinaridade, contextualização, democratização, pertinência e relevância social, ética e sensibilidade afetiva e estética, de modo a lhe permitir:

I - o conhecimento da instituição educativa como organização complexa na função de promover a educação para e na cidadania;

II - a pesquisa, a análise e a aplicação dos resultados de investigações de interesse da área educacional e específica; 
III - a atuação profissional no ensino, na gestão de processos educativos e na organização e gestão de instituições de educação básica.

Identificamos nesse artigo e seus incisos a explicitação do alargamento das funções dos profissionais da educação básica de um modo geral, e dos professores de modo particular, que além das atividades diretamente relacionadas ao ensino, também deverão possuir conhecimentos suficientes para atuarem na gestão e na pesquisa. No contexto da prática tal atuação já vem ocorrendo há algumas décadas, especialmente em se tratando da gestão das escolas; o que revela a existência de um movimento dialético entre a concepção/instituição das políticas educacionais e a prática profissional dos profissionais da educação. Esse movimento influencia inclusive a construção da identidade profissional dos professores, conforme discutiremos adiante.

Em se tratando da organização curricular, o Art. 12 da Resolução 02/2015 (BRASIL, 2015), estabelece que os cursos de formação de professores constituir-se-ão de três núcleos:

I - núcleo de estudos de formação geral, das áreas específicas e interdisciplinares, e do campo educacional, seus fundamentos e metodologias, e das diversas realidades educacionais[...]

II - núcleo de aprofundamento e diversificação de estudos das áreas de atuação profissional, incluindo os conteúdos específicos e pedagógicos, priorizadas pelo projeto pedagógico das instituições, em sintonia com os sistemas de ensino [...]

III - núcleo de estudos integradores para enriquecimento curricular [...]

A organização do currículo da formação de professores nesses três núcleos fornece elementos para que sejam reorganizados os cursos já existentes e orientará aqueles que ainda entrarão em funcionamento. Vale dizer ainda que, os cursos de licenciatura em Pedagogia, já estão organizados a partir dessa perspectiva, uma vez que em suas Diretrizes Curriculares aprovadas em 2006, já havia a orientação de que a organização curricular de tais cursos fosse contemplasse os núcleos acima expostos.

Em relação as possibilidades de formação inicial de professores para a educação básica indicadas na Resolução 02/2015 temos os cursos de: graduação em licenciatura; formação pedagógica para graduados não licenciados; e segunda licenciatura.

Para a compreensão acerca do previsto para a formação inicial de professores que atuam na Educação Profissional importa-nos especialmente trazer para a reflexão os cursos de formação pedagógica para graduados não licenciados, uma vez que a formação dos licenciados e, em certa medida, a oferta da segunda licenciatura para ampliar as possibilidades de atuação daqueles que já se encontram na docência constituem-se em formas consolidadas para a formação, tanto em termos de organização curricular quanto no que se refere a sua institucionalização como política de formação de professores para a atuação na educação básica; ao passo que, os cursos de formação pedagógica para graduados não licenciados, vêm constituindo-se historicamente em uma alternativa de formação de caráter emergencial, provisório e não obrigatório para a formação dos professores que atuam na Educação Profissional e Tecnológica.

Dito isso, no que se refere a Meta 15.9 do Plano Nacional de Educação (criação de cursos e programas especiais para assegurar a formação específica em nível superior aos professores da 
educação básica), identificamos nas novas Diretrizes para a formação inicial e continuada de profissionais do magistério da Educação Básica (BRASIL, 2015), a seguinte regulamentação:

Art. 14. Os cursos de formação pedagógica para graduados não licenciados, de caráter emergencial e provisório, ofertados a portadores de diplomas de curso superior formados em cursos relacionados à habilitação pretendida com sólida base de conhecimentos na área estudada, devem ter carga horária mínima variável de 1.000 (mil) a 1.400 (mil e quatrocentas) horas de efetivo trabalho acadêmico, dependendo da equivalência entre o curso de origem e a formação pedagógica pretendida.

§ 1으 A definição da carga horária deve respeitar os seguintes princípios:

I - quando o curso de formação pedagógica pertencer à mesma área do curso de origem, a carga horária deverá ter, no mínimo, 1.000 (mil) horas;

II - quando o curso de formação pedagógica pertencer a uma área diferente da do curso de origem, a carga horária deverá ter, no mínimo, 1.400 (mil e quatrocentas) horas;

III - a carga horária do estágio curricular supervisionado é de 300 (trezentas) horas;

IV - deverá haver 500 (quinhentas) horas dedicadas às atividades formativas referentes ao inciso I deste parágrafo, estruturadas pelos núcleos definidos nos incisos I e II do artigo 12 desta Resolução, conforme o projeto de curso da instituição;

V - deverá haver 900 (novecentas) horas dedicadas às atividades formativas referentes ao inciso II deste parágrafo, estruturadas pelos núcleos definidos nos incisos I e II do artigo 12 desta Resolução, conforme o projeto de curso da instituição;

VI - deverá haver 200 (duzentas) horas de atividades teórico-práticas de aprofundamento em áreas específicas de interesse dos alunos, conforme núcleo definido no inciso III do artigo 12, consoante o projeto de curso da instituição;

Apesar do seu caráter emergencial e provisório (considerando que serão avaliados no prazo de cinco anos sendo então estabelecido prazo para sua extinção), tal formação distingue-se e avança em relação ao estabelecido na Resolução CNE/CEB n.ㅇ 02/97³, e ao Parecer CNE/CP n.․ 05/064, especialmente no que se refere aos seus princípios e a carga horária que amplia-se

\footnotetext{
${ }^{3}$ Vale lembrar que a Resolução CNE/CEB n.o 02/97, estabeleceu como carga horária mínima para os cursos de complementação pedagógica 540 horas, incluídas as 300 horas da parte teórico prática. Compreendemos que tal carga horária inviabilizava a reflexão e a teorização acerca do processo de ensino aprendizagem, dos conteúdos curriculares, da avaliação, do mundo do trabalho, das questões metodológicas e da integração com outras disciplinas sendo insuficiente para a complexidade dos conhecimentos que envolvem a formação de professores.

${ }^{4}$ O Parecer CNE/CP n.o 05/06, por sua vez, ao dispor sobre os Programas Especiais de Formação Pedagógica de Docentes, orienta que estes passem a ser regidos pelo disposto nas Diretrizes Curriculares Nacionais para Formação de Professores para a Educação Básica, definidas pelo Parecer CNE/CP no 09/01 e na Resolução CNE/CP no 01/02, o que significa que a formação será baseada no desenvolvimento de competências profissionais. Em relação ao disposto na Resolução CNE/CEB n. 02/97, tem-se a alteração da carga horária dos cursos de formação pedagógica para os docentes que passam a ter minimamente 800 horas, das quais, no mínimo, 300 horas deverão ser dedicadas ao estágio supervisionado e, no mínimo, 500 horas às demais atividades formativas.
} 
consideravelmente sendo potencialmente capaz de melhorar as condições de aprofundamento da formação pedagógica dos professores que atuam na docência sem a formação mínima requerida para o exercício da profissão, que seja, a licenciatura.

Quanto a estratégia 15.3 da meta 15 do Plano Nacional de Educação que trata do estabelecimento de uma política nacional de formação de professores ainda não há regulamentações para o desenvolvimento de modelos de formação docente para a educação profissional que valorizem a experiência prática, ou seja, a certificação didático-pedagógica de profissionais experientes. Vale destacar que tal regulamentação é aguardada desde a aprovação da Resolução n. 06/2012 que "Define Diretrizes Curriculares Nacionais para a Educação Profissional Técnica de Nível Médio" ao estabelecer que:

Art. 40. A formação inicial para a docência na Educação Profissional Técnica de Nível Médio realiza-se em cursos de graduação e programas de licenciatura ou outras formas, em consonância com a legislação e com normas específicas definidas pelo Conselho Nacional de Educação.

$\S 10$ Os sistemas de ensino devem viabilizar a formação a que se refere o caput deste artigo, podendo ser organizada em cooperação com o Ministério da Educação e instituições de Educação Superior.

$\S 20$ Aos professores graduados, não licenciados, em efetivo exercício na profissão docente ou aprovados em concurso público, é assegurado o direito de participar ou ter reconhecidos seus saberes profissionais em processos destinados à formação pedagógica ou à certificação da experiência docente, podendo ser considerado equivalente às licenciaturas:

I - excepcionalmente, na forma de pós-graduação lato sensu, de caráter pedagógico, sendo o trabalho de conclusão de curso, preferencialmente, projeto de intervenção relativo à prática docente;

II - excepcionalmente, na forma de reconhecimento total ou parcial dos saberes profissionais de docentes, com mais de 10 (dez) anos de efetivo exercício como professores da Educação Profissional, no âmbito da Rede CERTIFIC;

III - na forma de uma segunda licenciatura, diversa da sua graduação original, a qual o habilitará ao exercício docente.

§ 30 O prazo para o cumprimento da excepcionalidade prevista nos incisos I e II do $\S 20$ deste artigo, para a formação pedagógica dos docentes em efetivo exercício da profissão, encerrar-se-á no ano de 2020.

$\S 40$ A formação inicial não esgota as possibilidades de qualificação profissional e desenvolvimento dos professores da Educação Profissional Técnica de Nível Médio, cabendo aos sistemas e às instituições de ensino a organização e viabilização de ações destinadas à formação continuada de professores.

Apesar desse artigo indicar que a formação dos professores deva se dar prioritariamente em cursos de graduação e programas de licenciatura, teme-se, pela trajetória das políticas educacionais no Brasil, que tal formação venha a ocorrer por meio das "outras formas" de habilitação para a docência. Diz-se isso, especialmente em função da possibilidade do "reconhecimento total ou parcial dos saberes profissionais de docentes, com mais de 10 (dez) anos de efetivo exercício como 
professores da Educação Profissional, no âmbito da Rede CERTIFIC", previsto no inciso II da referida Resolução.

Consideradas as possibilidades indicadas na Resolução 06/2012, embora não tenhamos regulamentado o exposto em seu Art. 40, e a Resolução 02/2015, compreendemos pelos dados disponíveis acerca da formação dos professores que atuam na Educação Profissional Técnica de Nível Médio, e que serão analisados na sequência, que os desafios que se põem para tal formação nos próximos anos são imensos.

\section{CARACTERIZAÇÃO DOS DOCENTES ATUANTES NA EDUCAÇÃO PROFISSIONAL TÉCNICA DE NÍVEL MÉDIO: DEMANDAS DE FORMAÇÃO E DESAFIOS PARA A POLÍTICA NACIONAL DE FORMAÇÃO DE PROFESSORES}

Diferentemente do que ocorre com os professores da Educação Básica em geral, os professores da Educação Profissional são, na sua maioria, do sexo masculino. Os dados de 2011 do INEP, por exemplo, apontam que 80,7\% das funções docentes da Educação Básica existentes no Brasil eram exercidas por mulheres. Já na Educação Profissional, tínhamos em 2012 um percentual de $45 \%$ das funções docentes do sexo feminino e $55 \%$ masculino.

De um total de 72.117 funções docentes relativas à educação profissional, em 2012, 69.039 estavam localizadas nas escolas urbanas, o que corresponde a 95,63\%, e apenas 3.078 nas escolas rurais $^{5}$ equivalendo a $4,27 \%$. Sobre a atuação dos professores na educação profissional por forma de articulação com o ensino médio, os dados informam que, em 2012, 58\% dos docentes atuavam nos cursos subsequentes, $33 \%$ no ensino médio integrado à educação profissional e $9 \%$ na forma concomitante.

Visto que a concentração dos docentes da EPTNM está nos cursos subsequentes consideramos importante destacar que a frequência nos mesmos exige que o estudante tenha concluído sua formação de nível médio para, posteriormente, receber a certificação que o habilita para exercer as funções de técnico de nível médio. Em termos de concepção, os cursos subsequentes tendem a focalizar a formação de mão de obra para o mercado de trabalho. O mesmo ocorre com os cursos concomitantes, cursados paralelamente ao ensino médio, caracterizados pela existência de duas matrículas do mesmo estudante não necessariamente na mesma instituição de ensino.

A organização curricular de tais cursos vem contribuindo para que a formação dos estudantes possua entre suas características a dissociação entre a formação profissional e a formação básica (a articulação entre os conhecimentos relativos à formação profissional e à formação básica poderiam possibilitar uma compreensão mais sólida das ciências e da realidade social, política, econômica, cultural em que os estudantes estão inseridos). É sabido que a maioria dos professores que atuam nos cursos concomitantes e subsequentes focalizam suas atividades de ensino na transmissão de domínio das técnicas relativas a determinada formação profissional, auxiliando os estudantes no desenvolvimento de competências definidas pelo mercado de trabalho. Oliveira (2011) destaca o caráter ideológico da formação técnica desvinculada de uma formação

\footnotetext{
${ }^{5}$ Esse número corresponde à soma das funções docentes da Educação Profissional Técnica de Nível Médio por localização geográfica (urbana e rural) do Censo Escolar de 2012.
} 
mais geral pela sua capacidade de conformar e adaptar o trabalhador às instituições de produção e consumo. Nesse sentido, declara que:

[...] no plano ideológico, a EP é chamada a conformar e adaptar o trabalhador, psíquica e emocionalmente, às novas bases materiais, tecnológicas, organizacionais e culturais da produção e do consumo; e, dentro disso, busca-se a formação de elementos subjetivos nos indivíduos, capazes de assegurar-lhes a sua adesão e disposição para adaptar-se alegremente às instituições e seus objetivos (OLIVEIRA, 2011, p. 73).

Reforça-se, assim, a tese de que a educação profissional técnica de nível médio, ao concentrar suas matrículas, especialmente, na forma de articulação subsequente (conforme podemos identificar nos dados do Gráfico 01) - o que repercute no número de funções docentes a ela vinculada - serve aos interesses do sistema produtivo vigente mais do que a uma formação politécnica de nível médio.

Os dados que seguem revelam que ao somarmos as funções docentes nas formas subsequente ( $58 \%$ ) e concomitante $(9 \%)$, chegamos a um percentual de $67 \%$ dos professores do total de funções docentes da EPTNM vinculados a tais formas de articulação entre a educação profissional técnica de nível médio e o ensino médio. Podemos dizer, então, que $67 \%$ dos professores da EPTNM atuam em cursos cuja formação está voltada, especificamente, para o trabalho produtivo.

Gráfico 01: Número de funções docentes da educação profissional por forma de articulação com o ensino médio Brasil, 2012

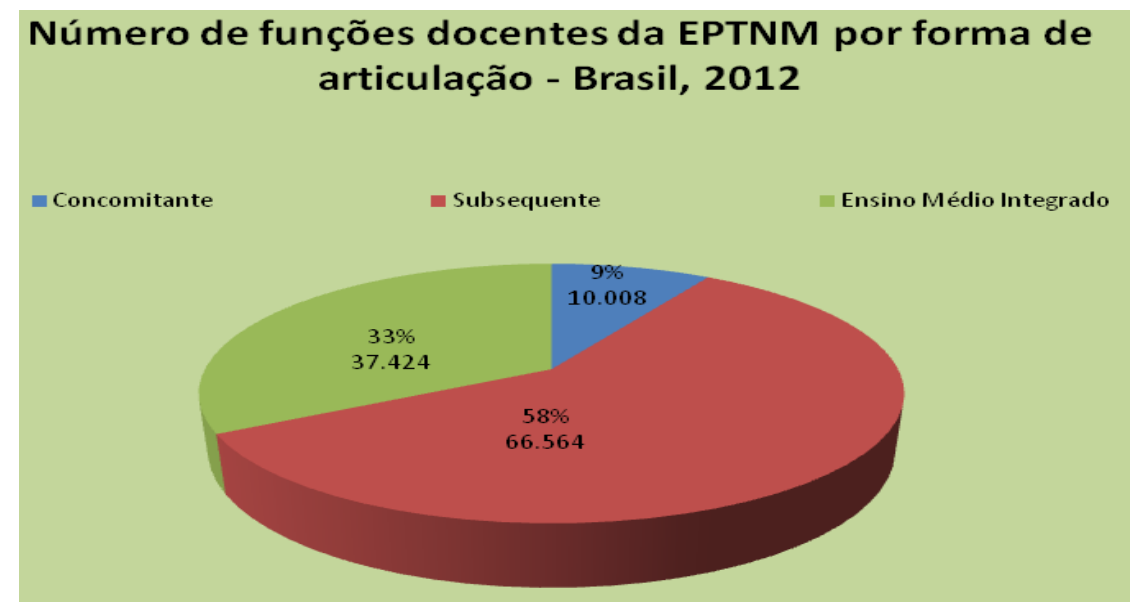

Fonte: INEP/MEC/ 2012/trabalhados por Silva F. L. G. R.

Em relação à formação dos professores que atuavam na educação profissional de nível médio no país, em 2012, os dados do INEP (Gráfico 02) apontavam que 90,75\% tinham formação superior, 9,20\% tinham formação de nível médio e 0,05\% tinham apenas o ensino fundamental.

Em relação ao percentual de professores com formação superior, ao tomarmos para análise os dados que seguem, veremos que a área de concentração da formação em nível superior dos professores da EPTNM não é a licenciatura, ou seja, a grande maioria dos profissionais que estão exercendo a docência são tecnólogos, bacharéis e engenheiros - sem habilitação para a docência.

Gráfico 02: Funções Docentes na Educação Profissional Técnica de Nível Médio por Escolaridade - Brasil, 2012 


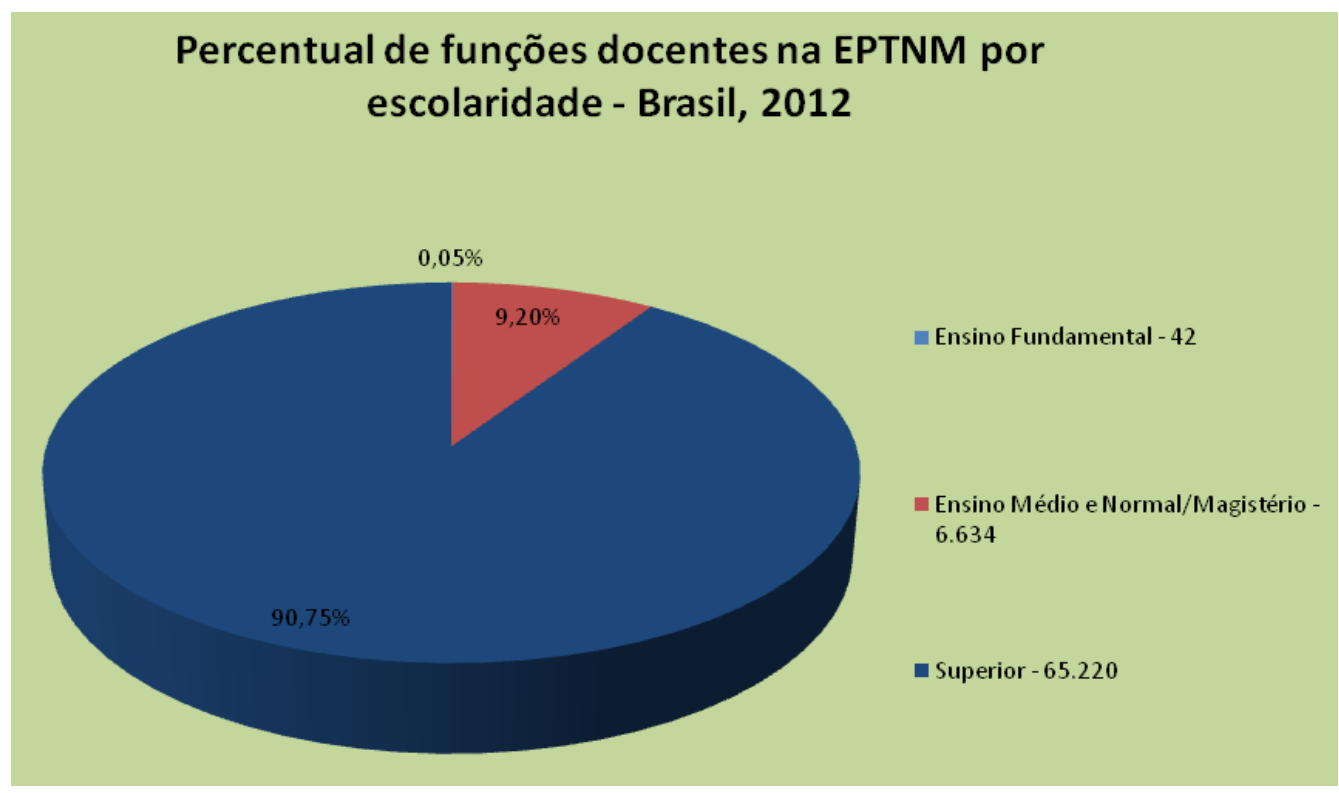

Fonte: INEP/ 2012/trabalhados por Silva F. L. G. R.

Visando aprofundar a radiografia da formação dos professores que atuam na Educação Profissional no Brasil, apresentamos, a seguir, um detalhamento sobre a formação superior desses professores em nível nacional e por regiões (Gráfico 03).

Na região Norte, em 2012, das 3.672 funções docentes na educação profissional, 57\% possuíam formação de nível superior (bacharelado ou tecnológico), 24\% tinham a formação superior com a complementação pedagógica e 19\% possuíam formação em licenciatura.

Na região Nordeste, em 2012, das 8.181 funções docentes na educação profissional, 47\% possuíam formação de nível superior (bacharelado ou tecnológico), 26\% tinham a formação superior com a complementação pedagógica e $27 \%$ possuíam formação em licenciatura.

Na região Sudeste, em 2012, das 36.549 funções docentes na educação profissional, 60\% possuíam formação de nível superior (bacharelado ou tecnológico), 12\% tinham a formação superior com a complementação pedagógica e $28 \%$ possuíam formação em licenciatura.

Na região Sul, em 2012, das 13.641 funções docentes na educação profissional, 46\% possuíam formação de nível superior (bacharelado ou tecnológico), 24\% tinham a formação superior com a complementação pedagógica e 30\% possuíam formação em licenciatura.

Na região Centro-Oeste, em 2012, das 3.177 funções docentes na educação profissional, 44\% possuíam formação de nível superior (bacharelado ou tecnológico), $28 \%$ tinham a formação superior com a complementação pedagógica e $28 \%$ possuíam formação em licenciatura. 
Gráfico 03: Funções Docentes na Educação Profissional com formação superior, com licenciatura e com complementação pedagógica, segundo as regiões geográficas - Brasil, 2012

\section{Formação Superior na EPTNM - Brasil e regiões, 2012}

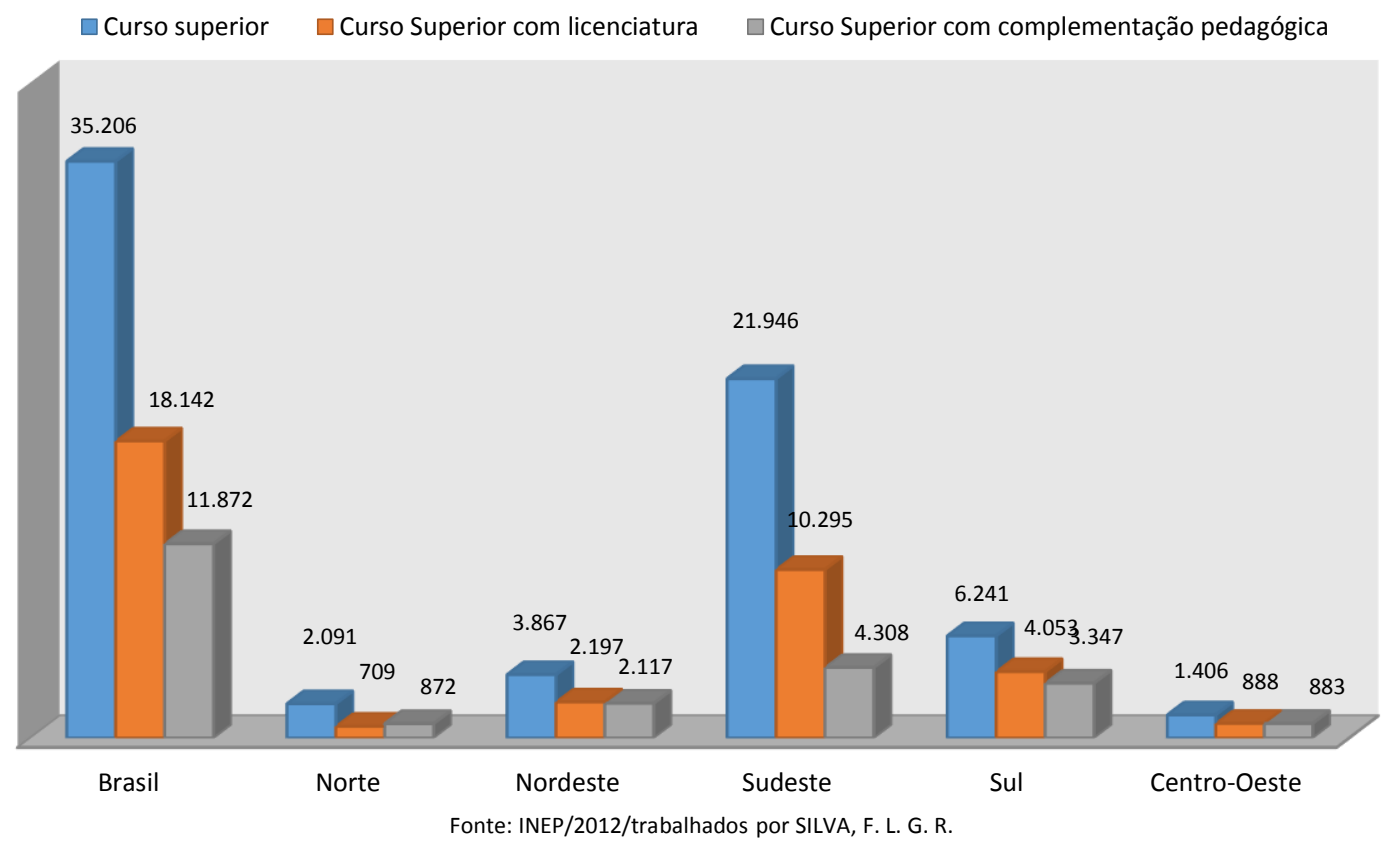

No Brasil, os dados do INEP 2012 (Gráfico 04) mostravam o seguinte quadro: das 65.220 funções docentes com formação superior que atuavam na educação profissional, 35.206 possuíam bacharelado, formação em engenharia ou em cursos tecnológicos, 18.142 haviam cursado licenciatura e 11.872 tinham formação superior com complementação pedagógica, ou seja, 54\%, $28 \%$ e $18 \%$, respectivamente.

Gráfico 04: Funções docentes na Educação Profissional com formação superior, com licenciatura e com complementação pedagógica - Brasil, 2012

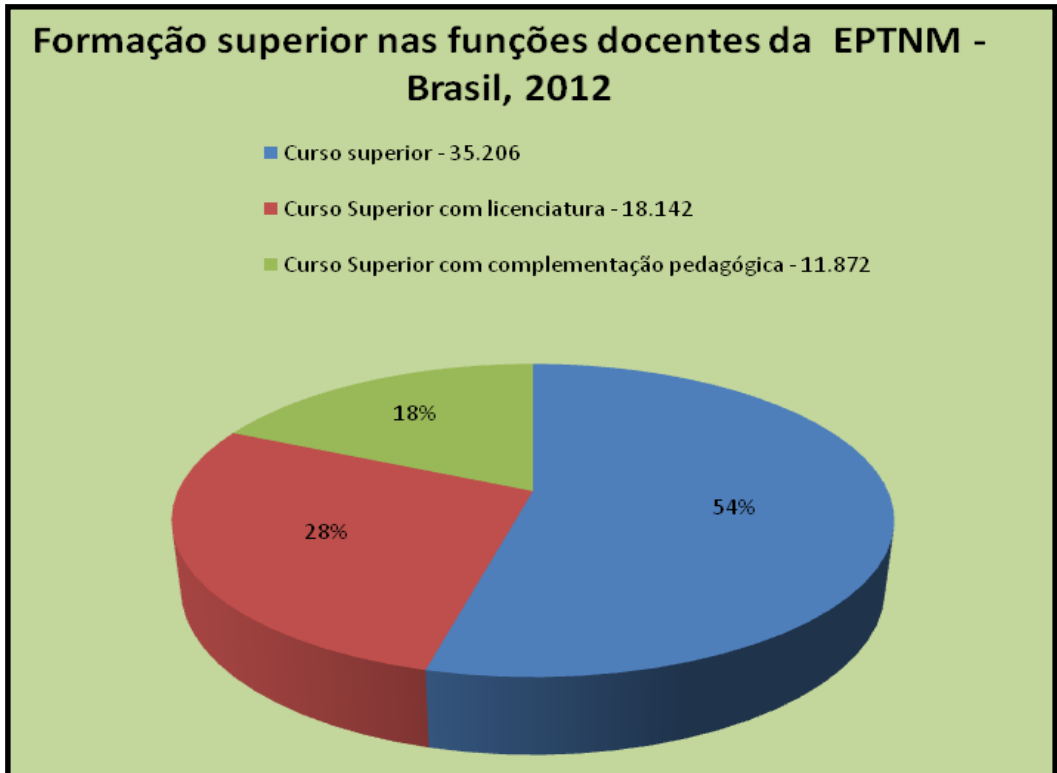

Fonte: INEP/ 2012/trabalhados por Silva F. L. G. R. 
Em síntese, conforme verificamos nos dados apresentados, a formação dos professores que atuavam na EPTNM em 2012 denunciam que dos 90,75\% das funções docentes que tinham formação superior, 54\% não possuíam licenciatura ou curso de formação pedagógica; 9,20\% tinham formação de nível médio; e 0,05\% tinham apenas o ensino fundamental. Tais índices somados revelam que $63,25 \%$ dos profissionais que atuam na docência da EPTMN não possuem a formação compatível legalmente estabelecida.

Considerando os dados apresentados podemos compreender o tamanho do desafio que se coloca para a formação dos professores da Educação Profissional de uma maneira geral. Apesar dos dados corresponderem a atuação na EPTNM há que se registrar que tais professores atuam em diferentes modalidades e níveis da educação profissional e tecnológica, desde a qualificação profissional até a pós-graduação.

Desse modo, considerando a abrangência da atuação dos professores da Educação Profissional e a teorização acerca da construção da identidade profissional podemos compreender a amplitude da influência das políticas públicas de um modo geral e fundamentalmente das políticas educacionais (no caso da EPT as políticas de formação dos seus professores e as formas, níveis e modalidades em que é ofertada a educação profissional), na construção ou fabricação das identidades profissional dos seus professores, sobretudo para o projeto nacional em desenvolvimento.

\section{A CONSTRUÇÃO/FABRICAÇÃO DA IDENTIDADE PROFISSIONAL DO PROFESSOR DA EPT: IMPACTOS DAS POLÍTICAS EDUCACIONAIS E DA SOCIALIZAÇÃO PROFISSIONAL/TRABALHO DOCENTE}

Em relação a reflexão acerca da construção da identidade profissional dos professores da Educação Profissional esclarecemos que a perspectiva que adotamos é histórica e sociológica. Tal opção nos possibilita compreender que a identidade profissional dos professores, assim como de qualquer outra categoria profissional, é forjada, construída ou fabricada no contexto social, político, econômico e cultural em que os indivíduos estão inseridos. Partimos da concepção de Dubar (2005, p. 135) para uma primeira tentativa de definição acerca do conceito de identidade. Para esse autor, a identidade consiste no:

[...] resultado a um só tempo estável e provisório, individual e coletivo, subjetivo e objetivo, biográfico e estrutural, dos diversos processos de socialização que, conjuntamente, constroem os indivíduos e definem as instituições (DUBAR, 2005, p. 136).

Ainda conforme Dubar (2009, p. 117-118), a socialização profissional consiste em "maneiras socialmente reconhecidas de os indivíduos se identificarem uns aos outros no campo do trabalho e do emprego".

Vista sob esse prisma, a compreensão da construção da identidade profissional do professor passa tanto pela socialização profissional quanto pela compreensão dos papéis que estes assumem nas instituições de ensino e, evidentemente pela sua formação. As atribuições do seu ofício, ou seja, os papéis que desempenham culminam com o desenvolvimento de condutas individuais, mas também institucionalizadas, e produzem uma identidade profissional. 
Em relação ao desenvolvimento da conduta profissional institucionalizada, destacamos, a partir de Lawn (2001, p. 120), que a tentativa de fixar, ou mesmo corrigir uma identidade é empreendida, entre outras formas, por meio de noções essenciais sobre a identidade do trabalhador, tais como apelos à sua função social e definição de seus papéis. Assim,

[...] alterações no trabalho do professor podem ser caracterizadas, quer como alterações fabricadas na sua identidade, quer como alterações técnicas nas competências de trabalho, nas tecnologias materiais e na gestão. De facto, é provável que as mudanças na representação do que é um professor, em diferentes períodos-chave deste século XX, revelem as alterações nas identidades estáveis, produzindo assim um sinal indubitável da reestruturação do trabalho (LAWN, 2001, p. 120).

Ainda segundo Lawn (2001), para entender como são fabricadas as identidades profissionais, é preciso levar em conta as mudanças ocorridas no mundo do trabalho em geral, e dos professores em particular, e compreender como os discursos políticos e a gestão das políticas educacionais contribuem na sua construção:

A produção da identidade envolve o Estado, através dos seus regulamentos, serviços, encontros políticos, discursos públicos, programas de formação, etc. É um componente essencial do sistema, fabricada para gerir problemas de ordem pública e de regulamentação. [...] A identidade é "produzida" através de um discurso que, simultaneamente, explica e constrói o sistema. A identidade do professor simboliza o sistema e a nação que o criou. Reflete a "comunidade imaginada" da nação, em momentos em que esta é crucial para o estabelecimento ou reformulação dos seus objetivos econômicos ou sociais, tal como se encontram definidos pelo Estado (LAWN, 2001, p. 118).

Entendemos, assim, que a identidade profissional dos professores é construída a partir das especificidades que envolvem o mundo do trabalho, aquelas próprias do trabalho docente e as políticas educacionais localizadas dentro de um contexto social, político, econômico e cultural, constituindo-se, portanto, no interior de um processo dialético.

Considerado o exposto, compreender o processo de construção ou fabricação da identidade profissional dos professores da EPT implica considerar tanto as políticas de formação de professores e as de educação profissional em geral quanto a sua implantação (ou seja, os impactos dessas políticas sobre o trabalho docente).

No que se refere as políticas de formação de professores para a EPT já evidenciamos na introdução desse texto que elas se caracterizam por medidas paliativas, aligeiradas e emergenciais.

Em que pese a concepção das políticas educacionais da educação profissional, a análise em perspectiva histórica, ilustra que essas são criadas e implementadas sob a lógica do capital, alinhando-se a perspectiva de qualificação da mão de obra para o mercado.

Dito isto, importa dizer que da mesma forma que compreendemos que se para ler a sociedade precisamos perquirir o que produz essa sociedade, para compreender a identidade profissional do professor da EPT precisamos concebê-la como resultado do seu processo formativo, mas também da sua socialização profissional, ou seja, do trabalho que realiza. 
Assim, compreendemos o trabalho docente a partir da sua inserção no sistema produtivo em vigor, tal como nos expõe Kuenzer (2011, p. 677):

[...] não escapa à lógica da acumulação do capital, direta ou indiretamente, pela compra da força de trabalho do professor e pela natureza de seu trabalho, que contraditoriamente forma sujeitos que atenderão às demandas do trabalho capitalista, cuja inclusão depende do disciplinamento para o qual a escola contribui. Ao mesmo tempo, o trabalho docente contribui, diretamente ou indiretamente, para a produção de ciência e tecnologia, pesquisando ou formando pesquisadores, e assim por diante. Ou seja, embora a finalidade do seu trabalho seja a formação humana, ele está atravessado pelas mesmas contradições que caracterizam o capitalismo.

Considerando essa lógica, o professor, como trabalhador assalariado, que vende sua força de trabalho, tende a respaldar sua ação pedagógica a partir das políticas educacionais criadas pelo Estado, inseridas em um movimento, como destacado pela autora, atravessado pelas contradições que caracterizam o estado capitalista e a sua manutenção.

É no interior das políticas educacionais e do cotidiano do trabalho docente, as quais possuem uma relação de interdependência, que a identidade profissional dos professores vai sendo constituída. Por meio das políticas educacionais, segundo Lawn (2001, p. 118), "as alterações na identidade são manobradas pelo estado, através do discurso, traduzindo-se num método sofisticado de controle e numa forma eficaz de gerir a mudança."

Com esse alerta de Lawn (2001), é possível afirmar que, por um lado, as políticas educacionais induzem à fabricação de uma identidade profissional convergente com o projeto societário da nação; por outro lado, que o projeto de nação também vai se construindo no interior das forças sociais. Entretanto é preciso considerar que, no Brasil, o jogo de forças sociais ainda pende, sobretudo, para o atendimento do que é de interesse da classe dominante. Por esse motivo, ao nos reportarmos para a incursão pelas trajetórias das políticas educacionais da última etapa da educação básica e da formação de professores no Brasil (especialmente da Educação Profissional e Tecnológica), é-nos possível compreender os motivos pelos quais elas assim foram concebidas. As políticas mudam para que o sistema permaneça.

Desse modo, dado o papel das políticas públicas de educação na construção da identidade profissional dos professores, as mudanças, segundo Lawn (2001), são geridas por diversas razões:

[...] primeiro, porque a identidade dos professores deve ajustar-se à imagem do projecto educativo da nação [...]; segundo, porque há poucas formas de, numa democracia, gerir eficazmente os professores, e a criação, através do discurso oficial, da identidade do professor é uma delas; terceiro, a identidade dos professores é flexível, no interior dos sistemas assentes em edifícios, exames e conhecimento universitário, podendo ser subtilmente manejada para enfatizar um aspecto, em vez de outro, dependendo das circunstâncias. A identidade do professor tem um potencial para não só reflectir ou simbolizar o sistema, como também para ser manipulada, no sentido de melhor arquitectar a mudança. A tentativa de alterar a identidade do professor é um sinal de pânico no controle da educação, ou um sinal da sua reestruturação (LAWN, 2001, p. 118-119). 
Em se tratando de ajustar a identidade profissional dos professores ao projeto de nação, o Estado cria mecanismos de controle sobre o trabalho docente, como qualquer outra forma de trabalho no capitalismo. Podem ser considerados mecanismos de controle sobre o trabalho docente desde a supervisão da ação pedagógica no contexto da sala de aula até a instituição de currículos escolares padronizados pelas diretrizes curriculares (que no caso da educação profissional tem envolvido especialmente a lógica do desenvolvimento de competências e habilidades profissionais) e a instituição de sistemas de avaliação que possibilitam medir o alcance dos resultados do processo do seu trabalho.

Por meio do discurso oficial, o Estado cria expectativas em relação ao papel da educação para o desenvolvimento econômico e social do país e contribui para que, no imaginário social e também dos professores, fiquem registradas suas responsabilidades com o processo educativo e com as finalidades traçadas para a educação em cada período histórico.

Nos discursos e políticas que envolvem os professores que atuam em qualquer uma das formas de oferta e níveis da Educação Profissional no Brasil, o enfoque tem sido, historicamente, o de formar mão de obra para o mercado de trabalho, tendo em conta a centralidade desta para o desenvolvimento econômico do país. Negligencia-se, desse modo, a possibilidade de a educação profissional desenvolver práticas educativas que contribuam para a formação de sujeitos que possam estar preparados para a inserção no mundo do trabalho compreendendo as contradições do sistema produtivo em que estão inseridos.

Dito isto, entende-se as razões pelas quais os discursos sobre o papel da Educação Profissional e consequentemente dos seus professores, e as políticas educacionais para esta modalidade da etapa final da educação básica, contribuem para fortalecer a concepção de que a EPT no Brasil destina-se quase que exclusivamente a formação de mão de obra para o mercado de trabalho, desconsiderando a possibilidade de uma formação crítica e com base científica sólida. Esta concepção repercute, por conseguinte, na construção de uma identidade profissional dos seus professores convergente com tais discursos e políticas. Os professores não apenas sentem-se pressionados pelo Estado e pela expectativa da sociedade, mas também responsabilizados pela formação da mão de obra altamente qualificada que o mercado requer e ainda pelo sucesso escolar dos estudantes - os quais são avaliados a partir dos resultados em exames nacionais e internacionais, que reproduzem a lógica produtivista da hegemonia capitalista mundial.

Seguindo essa lógica, as escolas e seus professores, ao não alcançarem êxito nessa tarefa, são desqualificadas e produzem argumentos para o Estado aumentar seu controle políticoideológico sobre a educação e mesmo para transferir para a iniciativa privada uma parte considerável da responsabilidade pela formação dos estudantes. A iniciativa privada, por sua vez, demonstra ser mais eficiente do que a escola pública no que tange a preparação da mão de obra para o mercado e a fabricação de sujeitos necessários para a reprodução da hegemonia do sistema.

É importante destacar que, na concepção político-ideológica que acaba por definir, em grande parte, as ações do Estado, é transferida por meio do discurso para a sociedade a ideia de que os problemas estão nos professores, e não na precarização do trabalho docente, na ausência de políticas de formação inicial e continuada sólidas, na falta de valorização dos professores e em sua má remuneração, na limitação ou ausência de estruturas físicas, didáticas e pedagógicas que 
ofereçam condições objetivas de realizar um trabalho com qualidade em relação à aprendizagem dos estudantes.

Além das questões que envolvem o trabalho dos docentes da educação básica, com o alargamento de suas funções que ultrapassam o ensino e alcançam a gestão da escola, conforme já exposto anteriormente, ao trabalho do professor da educação profissional outros elementos necessitam ser considerados para a compreensão da complexidade que o envolve devido a própria natureza da educação profissional técnica ou tecnológica, que, de acordo com Melo (2010, p. 2), compreende:

[...] atividades teóricas e práticas mais contíguas, e, por conseguinte, requer espaços físicos diferenciados além de salas de aula, como laboratórios, oficinas e, muitas vezes, ambientes externos do campo profissional. Exige ainda tempos e relações distintas entre professores e alunos, sobretudo nas aulas práticas, organizadas em grupos menores de alunos; visitas técnicas a contextos reais de atuação profissional; estágios supervisionados; orientações em projetos, pesquisas aplicadas, entre outras. Essa variabilidade traz implicações para o trabalho docente, conferindo-Ihe maior flexibilidade e proximidade na relação com os estudantes e com outros contextos e ambientes de trabalho.

Além dessas especificidades do trabalho docente na educação profissional, convém destacar a variedade de esferas, formas de oferta, níveis de atuação desses professores, que não só exige conhecimento teórico e prático a respeito da área do conhecimento em que atuam, mas também do mundo do trabalho. Em relação ao seu público, é importante considerar também a necessidade de o professor compreender de que modo os jovens e adultos de todas as idades constroem o conhecimento.

Paralela a essa questão, está a necessidade de os professores aprenderem a dosar e a dimensionar tais conhecimentos para as especificidades das formas de oferta da Educação Profissional (qualificação profissional, Ensino Médio Profissional conforme a especificidade de cada articulação: integrado, concomitante ou subsequente, ensino superior em nível tecnológico, bacharelado e licenciaturas, pós-graduação), mesmo sem ter tido a formação requerida para a docência.

Em se tratando das esferas de atuação do professor da educação profissional, localizamos, não só instituições públicas municipais, estaduais e federais, mas também privadas, notadamente as vinculadas ao Sistema $\mathrm{S}$, as organizações não governamentais, as centrais sindicais, fundações e empresas.

A existência dessa variedade de instituições, ou de atores que oferecem a educação profissional, além de revelar a complexidade do campo da educação profissional, também reflete a multiplicidade de concepções ideológicas, filosóficas, epistemológicas e políticas que repercutem não só no trabalho docente, mas também na construção da identidade profissional desses professores.

Essa variedade de atores não compõe apenas um campo complexo em relação as questões acima assinaladas, mas também apresenta diferenças em relação ao financiamento, aos objetivos, à estrutura, à organização do ensino, às formas de ingresso de estudantes e ao público-alvo. Além 
disso, há contradições acerca dos vínculos empregatícios, ao trabalho, remuneração e oportunidades de formação desses docentes. (MELO, 2010, p. 3).

É nesse contexto que as políticas educacionais, o trabalho docente, os discursos legais são forjados. E é sobre eles há uma lógica que se busca fabricar novas identidades profissionais, ou mantê-las, quando for o caso, de forma a potencializar a competência do professorado para alcançar os resultados propostos à EPT, colaborando, desta forma, com implementação de políticas educacionais existentes ou ainda com aquelas em gestação, de acordo com o projeto de nação em desenvolvimento.

\section{CONSIDERAÇÕES À CONTINUIDADE DO DEBATE:}

As discussões realizadas no decorrer desse texto trazem para o debate questões importantes para a reflexão acerca da formação dos professores que atuam na EPT, assim como para a construção ou fabricação da sua identidade profissional. Por um lado, pudemos identificar nas Diretrizes para a Formação de Professores, recentemente aprovadas, referenciais convergentes com uma concepção de formação preocupada com a relação teoria e prática (componentes práticos, pesquisa e extensão como princípios pedagógicos) e com a melhoria permanente da qualidade social da educação. Por outro lado, verificamos que, em se tratando da formação de professores da EPT, os programas de formação pedagógica ao serem mantidos, ainda se constituem uma alternativa de formação com caráter provisório, não havendo acenos para outra forma de formação a curto prazo que possa vir a substituir os programas historicamente instituídos para viabilizar tal formação.

Diante desse contexto, compreendemos que, apesar dos avanços em termos conceituais, presentes no texto das novas Diretrizes para a formação inicial e continuada dos profissionais da educação, ainda carecemos de uma política orgânica de formação de professores especialmente para a EPT. Dizemos isso considerando não só sua expansão no país, mas especialmente as lógicas que se põem para tal expansão e seu impacto sobre a construção ou fabricação de uma identidade profissional que diverge do projeto societário emancipatório para a classe trabalhadora, especialmente a mais empobrecida, defendido pelos intelectuais citados neste trabalho. $\mathrm{O}$ que temos em termos práticos, são políticas de EPT atravessadas pela concepção burguesa que perpetua a ideia de que para a classe trabalhadora basta ensinar um ofício que lhe possibilite prover minimamente seu sustento.

A ênfase que queremos dar ultrapassa a denúncia da ausência de uma política sistemática e orgânica de formação de professores para a EPT, que vem contribuindo para a fabricação de uma identidade profissional alinhada aos interesses do mercado e construída sob os princípios do capital. Ou seja, uma identidade profissional que tem sido eficiente e eficaz na formação de estudantes que vem produzindo e reproduzindo trabalhadores com pleno domínio da técnica, porém desprovidos da capacidade de construir saberes que Ihes possibilitem uma visão ampliada da realidade social, política, econômica e cultural em que estão inseridos.

Apesar de entendermos que o rompimento dessa lógica não é uma tarefa exclusiva da formação de professores, compreendemos que passa necessariamente por ela. Por esse motivo, a expectativa depositada nas atuais Diretrizes para a Formação de Professores é de que seu referencial possa, no contexto de sua implementação, se constituir em um contraponto às lógicas 
mercadológicas historicamente predominantes nas políticas de formação e nos projetos de criação dos cursos de complementação pedagógica, com reflexos sobre as práticas pedagógicas.

Por fim, reforçamos nossa conviç̧ão de que a instituição e implementação de uma política de formação de professores orgânica e comprometida com um novo projeto societário (e essa é uma decisão política que precisa ser tomada) poderá ser potencialmente capaz de influenciar na construção de uma identidade profissional que, no horizonte, permitirá uma educação emancipatória para os sujeitos que frequentam EPT. Tal expectativa converge com a concepção de Florestan Fernandes (1977, p.5, apud Moura, 2014), no sentido de que a "história nunca se fecha por si mesma e nunca se fecha para sempre. São os homens, em grupos e confrontando-se como classes em conflito, que 'fecham' ou 'abrem' os circuitos da história."

\section{REFERÊNCIAS BIBLIOGRÁFICAS}

1. BRASIL. Lei no 13.005, de 25 de junho de 2014. Aprova o Plano Nacional de Educação - PNE e dá outras providências. Brasília, 2014. Disponível em: <www.planalto.gov.br>. Acesso em: 30 de julho de 2014.

2. BRASIL. CNE/CP. Resolução n. 02, de 1을 de julho de 2015. Define as Diretrizes Curriculares Nacionais para a formação inicial em nível superior (cursos de licenciatura, cursos de formação pedagógica para graduados e cursos de segunda licenciatura) e para a formação continuada. Disponível em: http://portal.mec.gov.br/index.php?option=com_content\&view=article\&id=21 028\&ltemid=866 Acesso em: 09 de julho de 2014.

3. Resolução no 02, de 30 de janeiro de 2012. Define Diretrizes Curriculares Nacionais para o Ensino Médio. Disponível em: <http://portal.mec.gov.br/index.php?option=com_con tent\&view=article\&id=17417\&Itemid=866>. Acesso em: 13 dez. 2013.

4. CNE/CEB. Resolução no 06, de 20 de setembro de 2012. Define Diretrizes Curriculares Nacionais para a Educação Profissional Técnica de Nível Médio. Disponível em: $<$ http://portal.mec.gov.br/index.php?option=com_content\&view=article\&id=17417\&ltemid= 866>. Acesso em: 10 jan. 2014.

5. MEC. Educação Profissional Técnica de Nível Médio Integrada ao Ensino Médio. Documento Base. Brasília, 2007. Disponível em: <http://portal.mec.gov.br/setec/arquivos/pdf/ documento_base.pdf>. Acesso em: 10 jan. 2013.

6. CAMPOS, R. F. A reforma da formação inicial dos professores nos anos 1990: desvelando as tessituras da proposta governamental. 2002. 242 f. Tese (Doutorado em Educação) - Centro de Educação. Universidade Federal de Santa Catarina, Florianópolis, Santa Catarina.

7. CALDART, R. S.; PEREIRA, I. B.; ALEJANO, P; FRIGOTTO, G. (orgs.). Dicionário de Educação do Campo. Rio de Janeiro; São Paulo: Escola Politécnica Joaquim Venâncio; Expressão Popular, 2012.

8. DUBAR, C. A crise das identidades: a interpretação de uma mutação. São Paulo: Edusp, 2009.

9. Fontes, 2005.

A socialização: construção das identidades sociais e profissionais. São Paulo: Martins

10. EVANGELISTA, O.; SHIROMA, E. O. Professor: protagonista e obstáculo da reforma. In: Educação e Pesquisa, São Paulo, v. 33, n. 3, p. 531-541, set./dez. 2007. Disponível em: 
$<\mathrm{http}: / /$ www.google.com.br/url?sa=t\&rct=j\&q=\&esrc=s\&frm=1\&source=web\&cd=1\&ved=0CC sQFjAA\&url=http\%3A\%2F\%2Fwww.scielo.br\%2Fpdf\%2Fep\%2Fv33n3\%2Fa10v33n3.pdf\&ei=EZ _eUuq4GYfksATN2YLICw\&usg=AFQjCNELkIAs9Gkl3hdjcNsJsg065Irlbw\&bvm=bv.59568121,d.e W0>. Acesso em: 21 jan. 2014.

11. FRIGOTTO, Gaudêncio. A Relação da Educação Profissional e Tecnológica com a Universalização da Educação Básica. In: Educação e Sociedade, Campinas, v.28, n.100, Edição Especial, p.11291152, out.2007.

12. KUENZER, A. Z. A formação de professores para o ensino médio: velhos problemas, novos desafios. Educ. Soc., Campinas, v. 32, n. 116, p. 667-688, jul.-set. 2011. Disponível em: <http://www.cedes.unicamp.br>. Acesso em: 20 maio 2013.

13. Formação de professores para a educação profissional e tecnológica. In: DAKBEBM, A. I. L. F. et al. (orgs.). Convergências e tensões no campo da formação e do trabalho docente. Belo Horizonte: Autêntica, 2010. (Coleção Didática e prática de ensino).

14. LAWN, M. Os professores e a fabricação de identidades. In: Currículo sem Fronteiras, v. 1, n. 2, p. 117-130, jul./dez. 2001. Disponível em: <http://www.curriculosemfronteiras.org/vol1iss2articles/lawn.htm>. Acesso em: 12 dez. 2013.

15. MACHADO, L. R. S. O desafio da formação dos professores para a EPT e PROEJA. In: Educ. Soc., Campinas, v. 32, n. 116, p. 689-704, jul.-set. 2011.

16. Diferenciais inovadores na formação de professores para a educação profissional. In: Revista Brasileira da Educação Profissional e Tecnológica, Ministério da Educação, Secretaria de Educação Profissional e Tecnológica, v.1, n.1, jun. 2008. Brasília: MEC/SETEC, 2008.

17. MELO, S. D. G. Trabalho docente na educação profissional. In: OLIVEIRA, D. A.; DUARTE, A. M. C.; VIEIRA, L. M. F. DICIONÁRIO: trabalho, profissão e condição docente. Belo Horizonte: UFMG/Faculdade de Educação, 2010. CDROM.

18. MOURA, D. H. Educação Básica e Profissional no PNE (2014-2024): avanços e contradições. In.: Revista Retratos da Escola, Brasília, v. 8, n. 15, p. 353-368, jul./dez. 2014. Disponível em: $<$ http//www.esforce.org.br>

19. OLIVEIRA, Dalila Andrade. A reestruturação do trabalho docente: precarização e flexibilização. Educ. Soc., Campinas, v. 25, n. 89, p. 1127-1144, set./dez. 2004. Disponível em: $<$ http://www.cedes.unicamp.br>.

20. OLIVEIRA, Maria Rita Neto Sales. Organização Curricular da Educação Profissional. In: ARAúJO, R. M. L.; RODRIGUES, D. S. (orgs.). Filosofia da práxis e didática da educação profissional. Campinas, SP: Autores Associados, 2011.

21. SCHEIBE, L. O conselho técnico-científico da educação básica da capes e a formação docente. Cadernos de pesquisa, v. 41, n. 144, set./dez. 2011. Disponível em: <http://www.scielo.br/pdf/cp/v41n144/v41n144a09.pdf>. Acesso em: 14 jan. 2014.

22. _. Formação de professores no Brasil: a herança histórica. In: Revista Retratos da Escola, Brasília, v. 2, n. 2-3, p. 41-53, jan./dez. 2008a.

23. _. Políticas públicas para formação de profissionais da educação básica. In: VII Seminário de Pesquisa em Educação da Região Sul "Pesquisa em educação e inserção social", Anais..., Itajaí, SC, 2008b. CD-ROM. 
24. SHIROMA, Eneida Oto; CAMPOS, Roselane Fátima; GARCIA, Rosalba Maria Cardoso. Decifrar textos para compreender a política: subsídios teórico-metodológicos para análise de documentos. Perspectiva, Florianópolis, v. 23, n. 2, p. 427-446, jul./dez. 2005.

25. SILVA, F. L. G. R. Identidade profissional dos professores da educação profissional técnica de nível médio no Brasil e em Santa Catarina: desafios para a sua formação. 2008. Tese (doutorado em Educação) - Programa de Pós-Graduação em Educação, Universidade Federal de Santa Catarina (UFSC), Florianópolis, 2014.

26. VIEIRA, S. L. Políticas de formação e cenário da reforma. In:VEIGA, I. P.; AMARAL, A. L. Formação de professores: políticas e debates. Campinas, SP: Papirus, 2002. (Coleção Magistério: Formação e Trabalho Pedagógico). 